\title{
REANIMATING OTTOMAN HERITAGE SITES: ASSESSMENT OF ŠTIP
}

DOI: http://dx.doi.org/10.18509/GBP.2017.23

UDC: $930.85: 338.48$

\author{
Biljana Petrevska ${ }^{1}$ \\ Petar Namicev ${ }^{2}$ \\ ${ }^{1}$ Faculty of Tourism and Business Logistics, University Goce Delcev - Štip, Macedonia \\ ${ }^{2}$ Academy of Art, University Goce Delcev - Štip, Macedonia
}

\begin{abstract}
The study aims to achieve two goals: (i) To investigate the main prevailing factors for reanimating Ottoman heritage sites (OHS); and (ii) To assess possibilities for developing Ottoman heritage tourism product. This is done by elaborating the case of Štip (Macedonia), where five sites are identified as an Ottoman heritage. The analysis is based on a qualitative research method and incorporates: (a) Qualitative data analysis, by conducting interviews with stakeholders from local and central level who are directly or indirectly involved in issues related to the OHS; (b) Modified version of the model suggested by Krakover (2016) on heritage tourism formation; and (c) Secondary data sources analysis, by reviewing literature and historical data related to Ottoman history and OHS in Śtip. Generally, it was concluded that currently, the investigated OHS are in an inadequate appearance, so only scarce tourism valorization can be done. On the other hand, they all possess uniqueness, esthetic, architectural, historic and educational value, and may be related to many legends, myths and stories, thus been completely suitable to be presented as tourism products and part of a tourist route. From four assessed motives, the deliberate decision for tourism development, along with the potential economic benefits were surfaced as the main factors for reanimating OHS, thus boosting cultural tourism development. Finally, the study recommends design and development of an Ottoman heritage tourism product, but not as a separate product of Štip, but rather as a regional, or even national product, which may be promoted in a tailor-made tourist route.
\end{abstract}

Keywords: Ottoman heritage sites, Cultural tourism, Tourism product, Promotion.

\section{INTRODUCTION}

Cultural tourism supported by heritage sites, is one of the leading motives in tourism industry resulting in development of specific tourism products [1], [4]. The heritage sites are often destined to be leading or supporting spots on the tourism course generally being designed for specific groups of tourists and visitors.

While the prevailing motives may be led by supply [9] or demand side [10], this paper treats only the supply side being lead by the need to better clarify the supply side of the heritage tourism. Moreover, the study evaluates the possibility for reanimating the Ottoman heritage sites (OHS) by assessing the influence of several factors in the line of tourism valorization.

There is no current work in Macedonia that pays attention to such comprehensive approach like this research explores. Besides its contribution to the literature as a pioneer study in Macedonia's academic work, the study has practical significance since it recommends design of an Ottoman heritage tourism product and a specific thematic 
tourist route. It praises that local and regional authorities should induce more proactive attitude among tourism policy makers, which is easily manageable if creating tourism products tailored for specific target groups.

The paper is structured in several parts. After the introduction, Section two presents the research design which encompasses the methodology, target and sample locations. Section three poses the main findings and discussion, while the conclusion remarks and recommendations are noted in Section four. The research limitations and future work that may be addressed, are presented in the last part of the paper.

\section{RESEARCH DESIGN}

The study has two primary aims: (i) To identify the prevailing factors for reanimating OHS; and (ii) To assess possibilities for developing tailor-made tourist product based on valorization of OHS. To achieve these goals, the study is based on a qualitative research method and incorporates three sources of data: interviews; modeling; and secondary sources.

The interviews were conducted in December, 2016. During the interviewing, full notes were taken, upon which a qualitative data analysis was conducted to the collected information. The analysis process contained two steps: summary and compilation. All collected information and literature material was summarized into items. Then the items with similar meaning were categorized together and conclusion was drawn. The interviews were undertaken by an open-ended questioning sessions which allowed collection of more subjective and qualitative data. Prior to entering the field survey, a seven-step interview protocol was designed.

\begin{tabular}{|c|c|}
\hline INITIAL FORMATION & MATURE FORMATION \\
\hline Step 1: Existence of an Ottoman landmark & \\
\hline Step 2: Identification of stakeholders & Step 1: Supply improvements \\
\hline Step 3: Mapped as a tourist attraction & \\
\hline & Step 2: Specialized tour guides \\
\hline & \\
\hline
\end{tabular}

Figure 1. Initial phase

(Modified and adjusted upon Krakover [6: 8])
Figure 2. Mature phase

(Modified and adjusted upon Krakover [6: 13])

The interviews contained direct, clear and tailored questions that led us to initial conclusions. Yet, the evidence from the field was supplemented with the modified version of a model [6] which main intention is to assist in a heritage tourism formation. We have adjusted and altered the model to better fit the sampled sites. The model offers a logical order of steps summarized in two major phases: (i) Initial phase (Fig. 1); and (ii) Mature phase (Fig. 2). Both phases incorporate limited steps, so some modifications were made. The initial phase outlines several steps that are logical and were supported by the field evidence. In step 1, we have marked an existence of an Ottoman landmark, which can be a mosque, bezisten, bridge etc. Step 2 was identification of stakeholders who assessed the possibilities for reanimating these landmarks. In the final step 3, we investigated the potentials for mapping the landmarks as tourist attractions. The second phase of the model is the mature phase, which presents more advance steps in tourism product formation. In this manner, the first step consisted of the supply improvements represented as supplementary attractions related to the Ottoman culture. In step 2 we have investigated 
the presence of specialized tour guides, while step 3 was examination of potentials for creating an Ottoman heritage tourist route and the possibilities for their local, regional or even national valorization.

In addition to the research method and modeling, a consultation of secondary sources was conducted. It included review of literature, such as historical data as well as materials that directly or indirectly deal with Ottoman history and OHS, thus adopting a multidisciplinary approach. Furthermore, brochures, maps, and websites were analyzed to better understand the broad context. Information collected via these procedures enabled triangulation and validation of data.

The target group for interviewing consisted of key stakeholders from local and central level who are directly or indirectly involved in issues related to the OHS. Total of nine interviews were held with an average conversation time of 22 minutes (Table 1).

Table 1. Summarized results on general interviewee data

\begin{tabular}{|l|l|}
\hline \multicolumn{1}{|c|}{ Item } & \multicolumn{1}{c|}{ Description } \\
\hline Position & $\begin{array}{l}\text { 2 Historians of Art, 4 Councilors for conservation, a Historian, a Councilor at } \\
\text { the Municipality’s cadastre, an Inspector at the Ministry of Culture }\end{array}$ \\
\hline Age & between 35-87 (average: 61 years) \\
\hline Sex & 1 female (11\%); 8 male (89\%) \\
\hline Time for interviewing & $20-35$ min (average: 22 min) \\
\hline
\end{tabular}

The study investigated the presence of four factors (F) for enhancing cultural tourism by reanimating Ottoman landmarks in Štip, such as: F1: Deliberate decision; F2: Revival of a Past; F3: Economic benefit; and F4: Promotion.

Based upon literature review [3], five sites were identified as Ottoman heritage (Fig. 3). Sultan's bridge Emir Ḱučuk (Fig. 3, No. 1) was built in 1672 when it played important communication role. During the First Balkan War the demarcation line passed through this bridge, which divided Štip to a Bulgarian and Serbian part. Being located at the entrance of the city, nowadays, the bridge has cultural and historical significance.

Clock Tower (Bay's Tower) (Fig. 3, No. 2) is dating from the 17 century. Two stories are narrated even nowadays. According to the first story, the tower was built by a Bay in order to protect himself and the family, while according to the second, a Bay was in love with a girl from Štip who asked for this landmark in return of her forced love. Today, it represents one of the symbols of Štip.

Husamedin Paša Mosque (Fig. 3, No. 3) is located on a hill from the left side of the river Otinja. It was built in the 17 century and has specific architecture representing the early Ottoman and the late Byzantine style. The travel writer Evlija Celebi mentioned it in his reportage in 1662. Despite the restoration in 1950s, today the mosque is out of function.

Kadin Aga Mosque (Fig. 3, No. 4) was built in the 19 century and it acts as an active religious facility for Muslims living in Štip.

Bezisten (Fig. 3, No. 5) is located in the center and is assumed to be constructed in the 16 or 17 century when it served as the main market street. Later on, it was used as a prison until was ruined in a fire. After the restoration in a full stone appearance, it has three inner rooms and a remarkable dome. Today is one of the most representative examples of the Ottoman architecture and serves as an exhibition area. 


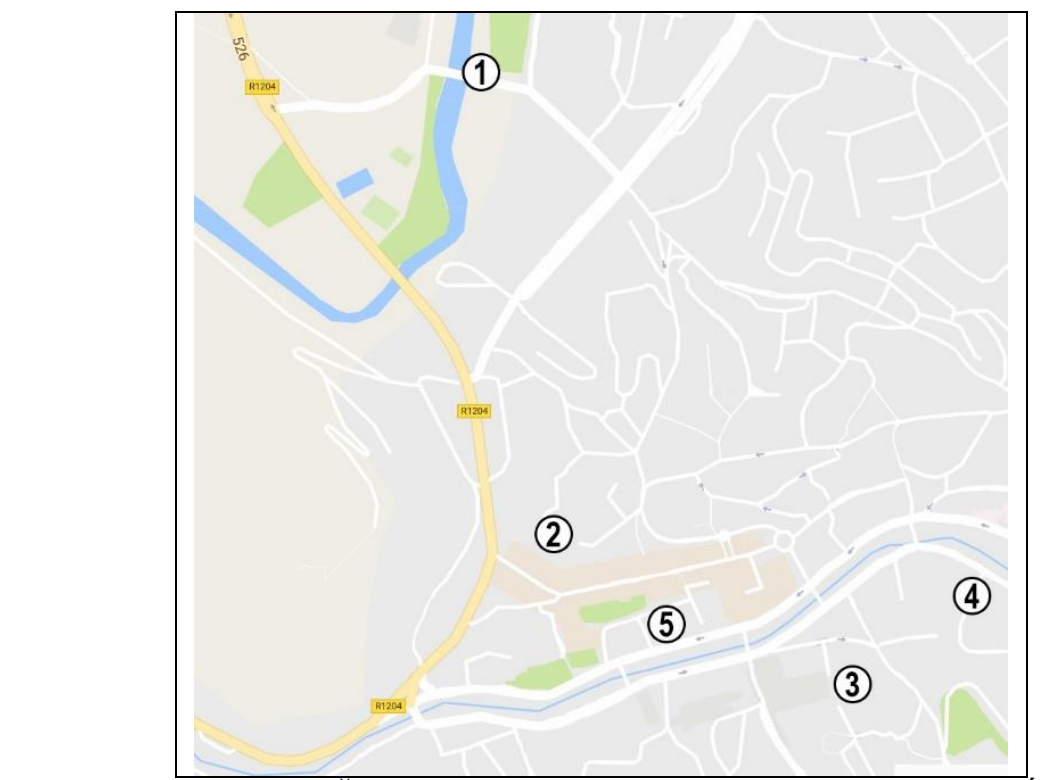

Figure 3. Map of Štip with sampled sites: 1 - Sultan's bridge Emir Ḱučuk, 2 - Clock Tower, 3 - Husamedin Paša Mosque, 4 - Kadin Aga Mosque, 5 - Bezisten

\section{FINDINGS AND DISCUSSION}

The degree to which the investigated landmarks are prepared to be offered as tourism heritage sites, differs greatly. They are not concentrated in one entity, but are rather dispersed in various locations. Despite their authenticity and historic value, they are not registered as belonging to a protected area. On a contrary, some of them are located in the city center in the administrative section of the city. Except for the Kadin Aga Mosque (Fig. 3, item No. 4) which is an active religious facility for the Muslims living in Štip, and the Bezisten (Fig. 3, item No. 5) which occasionally serves as an exhibition place, the rest of the OHS are passive. They are not marked on any city or regional tourist map, and there is no tourist signalization how to drive/walk to them. The local tourist guides do not include them in any of the tourist routes. Yet, there is a high awareness of the positive impacts that OHS may bring to tourism development of the city and the region. Beside the past efforts for revitalization of some of the landmarks, the limited funds from local and central level resulted in undertaking only partial activities (like: renovation of the floor and the roof of the Bezisten). There was a project from the Ministry of Culture for conservation of the Husamedin Paša Mosque (Fig. 3, item No. 3), but it was never implemented. Additional intervention is a must for all sampled sites since the current protection is not sufficient.

After detailed observations during the field survey, it was concluded that Štip with its OHS is still in the initial phase, but it is rapidly going to the maturity phase. Yet, much design work of relief, restitution, restoration, drawing, mechanical, electrical and structural strengthening should be undertaken which is strongly depended on local, regional and national funding.

After data sublimation, it was concluded that the key stakeholders who are directly or indirectly involved in issues related to the OHS, assessed two motives as leading for the reanimation: (i) Deliberate decision for tourism development; and (ii) Economic benefit. In the case of the deliberate decision, the intention was to investigate whether the OHS may contribute to tourism development by evoking the history. $89 \%$ agreed that investing in the Ottoman sites should be initiated only if perceiving them as a cultural heritage that face an important chapter in the national history. This supports the finding that the OHS 
tend to preserve and animate diverse features such as structures, history, religion and folklore, as noted in [11]. The rest of the interviewees representing $11 \%$ partially agreed, thus putting an accent that there is a technical documentation of the Municipality of Stip for reconstructing the sites, but additional initiative needs to be undertaken. Maybe not all of the sites may be valorized in tourism manner, but all of them present facilities with historical background. So, regardless the economic benefit, the sites should be revitalized and protected.

In the case of economic benefit, the intention was to investigate whether OHS are perceived to lead to economic benefits, so they may be developed as points of interest or tourist attractions. 78\% stated that if the local government along with a support from the central government allocate investment funds, the sites may be renovated and reanimated. If the Municipality of Štip undertakes measures and activities for investing in conservation and protection of these sites, particularly if identifies them as strategic points of local or regional interest, they may be perceived as potential tourist attractions. By developing OHS it is expected to gain economic benefits that may enhance local and regional development, which supports the findings as in [7] and [5]. On the other hand, $11 \%$ of the respondents stated that the current sites possess only historical values which may not lead to economic benefits. The rest of $11 \%$ partially agreed on this issue. Namely, the interviewees responded that only the Bezisten as a facility for cultural events (exhibitions, performances, art events, poetry readings, plays etc.) may bring some economic benefits, which may not be the case with the mosques. Maybe if the mosques are transformed into cultural and not religious facilities, then can be developed as points of interest to broader visitors. However, tourism is assessed as an industry that generates large negative impacts particularly to the cultural landmarks, so its development must be fully controlled. The economic benefits that result upon tourist flows are more than welcomed for the local and regional development, but only if being thoroughly supervised.

Due to almost identical answers, no clear conclusion can be drawn when investigating the motif for the presence of the revival of a glorious Past when people of different affiliations were living in harmony. Namely, $44 \%$ replied affirmative stating that having sites dated from $16^{\text {th }}$ and $17^{\text {th }}$ century revives the past when the Ottoman empire was dispersed over the Macedonian territory. Particularly the Bezisten and the Clock Tower may be used as facilities to revitalize the ancient history when people of different affiliations were living together. On the other hand, 56\% replied negatively about the presence of this motif. Except for the Kadin Aga Mosque, none of the sites is active as a religious facility, so they cannot revive the past. None is related to the municipal holidays, nor is associated to some important historical local or regional event.

The final factor was related to the possibilities to promote the Ottoman heritage landmarks as tourist attractions and hence to reanimate them. Once again, we were unable to make clear conclusion due to divided opinions. To be exact, $44 \%$ agreed and $23 \%$ partially agreed that all landmarks may attract interest to be visited, but not all of them may be explored in cultural manner. Currently, only the Bezisten may be promoted as a facility that may be explored for the purposes of developing cultural tourism. The Husamedin Paša Mosque and the Kadin Aga Mosque, may have a double role i.e. to be promoted as active religious structures, but simultaneously as places for performing religious activities that may attract tourists and visitors. Opposite to this, 33\% of the interviewees thought that the current landmarks should be promoted only as landmarks with historical values and archaic elements that make them authentic. Thus, there are no possibilities to perform 
some cultural events that may attract visitors. According to these respondents, the municipality should invest in a brand new facility that would serve only and particularly for cultural purposes. In this line, the interviewees assessed a danger of devastation of the cultural-historical heritage due to negative impacts that tourism may bring.

\section{CONCLUSION AND RECOMMENDATIONS}

The research intended to identify approaches to transform the OHS into tourism points of interest according to the perception of the stakeholders. From four investigated motives, the deliberate decision for tourism development based on history, along with the economic benefits are identified as the most prevalent factors that may support cultural tourism development in Štip, by designing Ottoman heritage tourism product. It was found that by reanimating the OHS, cultural tourism may be developed as a generator of an economic growth not only in Štip, but in the wider East region of Macedonia, thus acting as a factor for economic self-sustainability of certain locations, products or routes. So far, very modest funds are allocated for reconstruction of the OHS in Štip, dominantly by the Ministry of Culture implemented by the City Museum, and modestly by the Municipality of Štip. The Turkish Cooperation and Coordination Agency (TIKA) has successfully implemented several projects for preserving historical heritage in Macedonia, being so far focused only on the restauration of three mosques in Skopje, but none in the Eastern part of Macedonia. Consequently, the Government should allocate funds for preserving ancestral legacy in order to pass to the future generations the common historical and cultural heritage.

In the meantime, the number of tourists visiting the East region doubled from 12,021 in 2006 to 25,907 in 2015 . However, this positive trend could not last long if not introducing new tourism products that will promote the local area and the region from different perspective. On the other hand, according to the regional Strategy for tourism development [2: 36], four strategic areas are defined: (i) Development of human and institutional capacities; (ii) Tourist infrastructure; (iii) Tourist offer; and (iv) Marketing and branding. Within each strategic area, several strategic priority targets are defined. If having in mind the strategic target referring developing a specific tourism product, two measures are noted [2: 38]:

(i) Development of a tourism product based upon cultural-historical heritage (measure No. 3); and

(ii) Designing tourist packages (measure No.5).

The field research fully conformed to these strategic measures since it revealed that Štip offers significant cultural and historical values dating from the Ottoman period that are insufficiently presented, utilized and valorized despite the opportunity for development of an attractive tourism product. Not all sampled OHS have attractive location, but they all possess uniqueness, esthetic, architectural, historic and educational value. They are all evocative sites related to many legends, myths and stories, thus been completely suitable to be presented as tourism products and part of a tourist route. This is also supported by the activity noted in the annual Program for Promotion and Support of Tourism for 2017 prepared by the national Agency for Promotion and Support of Tourism of the Republic of Macedonia, where it is foreseen to prepare a "Guide through the Ottoman landmarks" as a promotional activity for a specific target group [8: 207].

The current tourism supply is uncoordinated and unorganized in terms of creating a specific tailor-made tourism product on local and regional level as well. The process of creating such product should take into consideration the needs of the traveler, visitor or 
the tourist, along with the expectations and motivation, which must be included in a tourist route. Such thematic route that will offer exploration of the OHS may be a solid base and opportunity to expand tourism development, particularly in time of ever growing tourism demand for such a modern form of non-stationary type of visit. This kind of route requests mapping of the OHS on local, regional and national tourist maps as a precondition for developing and promoting tourist routes that will discover Ottoman history. By all means, the route may be expanded with other points of interest from Stip, like the Museum of the town Štip whereas the exhibition from the Ottoman period is presented, or a short walk to the Stip Fortress known as Isar dating from the early middle ages, and simultaneously to taste Turkish meals and desserts.

Based on the field work findings, the paper recommends some future actions in the line of enhancing modest development of cultural tourism in Štip, which may allow the OHS to be accessible for locals and visitors:

○ To develop and conduct activities for visitors and tourists by observing the OHS as parts of a past local culture;

$\circ$ To create balance between the protection of the OHS and the tourism flows in the line of achieving sustainability;

○ To design and develop an Ottoman heritage tourism product, but not as a separate product of Štip, but rather as a regional, or even national product; and

- To promote a tailor-made thematic tourist route that will contribute to creating autochthonous and competitive tourism supply for better positioning on tourism market.

\section{LIMITATIONS AND FUTURE WORK}

The research was limited by several factors that can also serve as productive starting points for future work.

○ First, it employed a relatively small set of factors that acted as research hypotheses and could be enhanced by introducing other aspects of investigation to better identify how to reanimate the Ottoman heritage more efficiently from tourism perspective;

- Secondly, the findings are drawn from a relatively small sample of interviewers, so the future work may focus on expending the list of respondents with tourist guides, experts from tourism business etc.;

- Finally, the investigation may be spread to other locations in Macedonia in order to gain representation on this issue for the entire country, as well as to employ multiple models and theories relevant to the assessment of the investigated subject.

Yet, this article may assist in better understanding the possibilities for tourism valorization of the OHS upon which specific development strategies may be set. Overall, the research generates useful findings and points to valuable directions for further work.

\section{REFERENCES}

[1] Bond, N., Packer, J. \& Ballantyne, R. Exploring visitor experiences, activities and benefits at three religious tourism sites, International Journal of Tourism Research, vol. 17, 5, pp 471-481, 2015.

[2] Center for Development of the East Planning Region of Macedonia. Strategy for development of tourism in the East planning region with Action plan (2016-2025), Stip, 2015a.

[3] Center for Development of the East Planning Region of Macedonia. Study for the condition of potentials for development of tourism in the East planning region, Štip, 2015 b. 
[4] Dinis, A. \& Krakover, S. Niche tourism in small peripheral towns: The case of Jewish heritage in Belmonte, Portugal. Journal of Tourism Planning and Development, DOI:10.1080/21568316.2015.1114014, 2015.

[5] Frey, B. S. \& Steiner, L. Pay as you go: A new proposal for museum pricing, Museum Management and Curatorship, vol. 27, 3, pp 223-235, 2012.

[6] Krakover, S. A heritage site development model: Jewish heritage product formation in south-central Europe, Journal of Heritage Tourism,

DOI:10.1080/1743873X.2016.1151430, 2016.

[7] Nasser, N. Planning for urban heritage places: Reconciling conservation, tourism and sustainable development, Journal of Planning Literature, vol. 17, 4, pp 467-479, 2003.

[8] Official Gazette of the Republic of Macedonia No. 192 from 17.10.2016.

[9] Richards, G. Production and consumption of European cultural tourism, Annals of Tourism Research, vol. 23, 2, pp 261-283, 1996.

[10] Richards, G. \& Fernandes, C. Religious tourism in northern Portugal. In: G. Richards (Ed.), Cultural tourism: Global and local perspectives, Binghamton, NY: Haworth, 2007.

[11] Sautter, E. T. \& Leisen, B. Managing stakeholders: A tourism planning model, Annals of Tourism Research, vol. 26, 2, pp 312-328, 1999.

[12] State Statistical Office. Regions in the Republic of Macedonia, 2015. Skopje, Macedonia, 2015. 